\title{
ANALISIS PERUBAHAN LUAS LAHAN MANGROVE DI KABUPATEN POHUWATO PROPINSI GORONTALO DENGAN MENGGUNAKAN CITRA LANDSAT
}

\author{
Esry Tommy Opa \\ Staf Pengajar pada Program Studi IImu Kelautan, \\ Fakultas Perikanan dan IImu Kelautan. UNSRAT. Manado 95115.
}

\begin{abstract}
A study on spatial evaluation of mangrove resource was carried out in Pohuwato Regency, the province of Gorontalo, for 3 months. The mangrove resources in this area have been exploited to build ponds, houses and for firewood. As the result, there was a significant decrease in mangrove population. In this study, main data were gathered from Landsat TM Satellite Image 2000-2001 and 2009-2010, and others data collected from the field and interviews with local villagers. Aproximately 60 sampling points were observed and examined. Normalized Difference Vegetation Index (NDVI) was applied to determine the extent of mangroves and its changes. In 2000-2001, the mangrove area was about 7,007.67 $\mathrm{Ha}$, and reduced to 3,034.53 $\mathrm{Ha}$ in 2009-2010.
\end{abstract}

Keywords: Mangrove, Pohuwato, Vegetatioin Index, NDVI, Landsad.

\section{PENDAHULUAN}

Kabupaten Pohuwato, Provinsi Gorontalo, terkenal dengan jalur hijau mangrove dan keberadaan mangrove sebagai ekosistem pantai cukup luas terbentang dari Kecamatan Paguat hingga Kecamatan Popayato Barat. Saat ini, keberadaannya kian terancam dan memprihatinkan, dimana sebanyak 70 persen dari luas kawasan hutan mangrove ini terindikasi mengalami kerusakan, dan sebagian besar di antaranya tergolong rusak parah. Dari luasan 25.688,09 hektar hutan mangrove yang ada di Kabupaten Pohuwato, telah terjadi kerusakan berat seluas $14.017,58$ hektar, dan rusak 7.546,89 hektar sedangkan kondisi baik atau tidak rusak hanya tersisa 4.123,62 hektar.

Faktor penyebab rusaknya hutan mangrove di daerah ini antara lain adalah pemanfaatan yang tidak terkontrol, karena ketergantungan masyarakat yang menempati wilayah pesisir sangat tinggi, konversi hutan mangrove untuk berbagai kepentingan, seperti perkebunan, tambak, pemukiman, kawasan industri, wisata dan lain-lain, tanpa mempertimbangkan kelestarian dan fungsinya terhadap lingkungan sekitar.

Kabupaten Pohuwato adalah salah satu daerah di Indonesia yang mengalami kerusakan hutan mangrove terparah. Dalam situasi seperti ini, habitat dasar dan fungsi hutan mangrove menjadi hilang, dan kehilangan ini jauh lebih besar dari nilai penggantinya, di samping informasi kajian luasan hutan mangrove daerah ini belum memadai. Untuk itu dilakukanlah suatu penelitian mengenai luasan mangrove di pantai Selatan Gorontalo, tepatnya di kabupaten Pohuwato.

Metode yang digunakan dalam pemantauan luas hutan mangrove yaitu teknologi penginderaan jauh, menggunakan data citra Landsat TM. Kelebihan metode ini yaitu dapat memantau wilayah yang luas dalam waktu yang hampir bersamaan dan berkesinambungan termasuk daerah yang sukar dijelajahi dan dapat merekam kondisi perairan pesisir yang bersifat dinamis dalam waktu singkat (Susilo, 1997). Penelitian ini bertujuan untuk mengevaluasi perubahan luasan mangrove di pantai Selatan kabupaten Pohuwato provinsi Gorontalo dengan memanfaatkan data citra Landsat TM multi temporal yaitu data tahun 20002001 dan 2009-2010.

\section{METODE PENELITIAN}

Penelitian ini dilakukan di wilayah kabupaten Pohuwato provinsi Gorontalo. Sebanyak 60 titik atau lokasi diamati secara saksama dalam batas wilayah pesisir antara koordinat $00^{\circ} 25^{\prime} 19.0$ "LU (Tanjung Panjang)-00 33'15.9"LU (desa Lomuli, Lemito); $121^{\circ} 20^{\prime} 13.6$ "BT (desa Sijoli, Molosipat)-122 $07^{\prime} 11.5^{\prime \prime}$ BT (tambak di desa Mo- 


\section{Perubahan Luas Lahan Mangrove}

lamahu). Observasi secara visual juga dilakukan terhadap kehadiran mangrove dalam batas-batas koordinat tersebut seperti disajikan pada Gambar 1.

Penelitian dilakukan dalam dua tahap, yaitu analisis data citra dan ground check. Alat dan bahan yang digunakan dalam penelitian ini terdiri dari dua macam, yaitu untuk pengolahan data citra dan survei lapangan.

Penelitian ini berdasarkan analisis data citra Satelit Landsat TM dengan menggunakan metode indeks vegetasi (NDVI). Lokasi ground check titik-titik pengamatan vegetasi mangrove ditentukan secara purposif berdasarkan keterwakilan lokasi kajian, sesuai dengan hasil pengolahan citra awal untuk daerah-daerah mangrove yang mengalami perubahan.

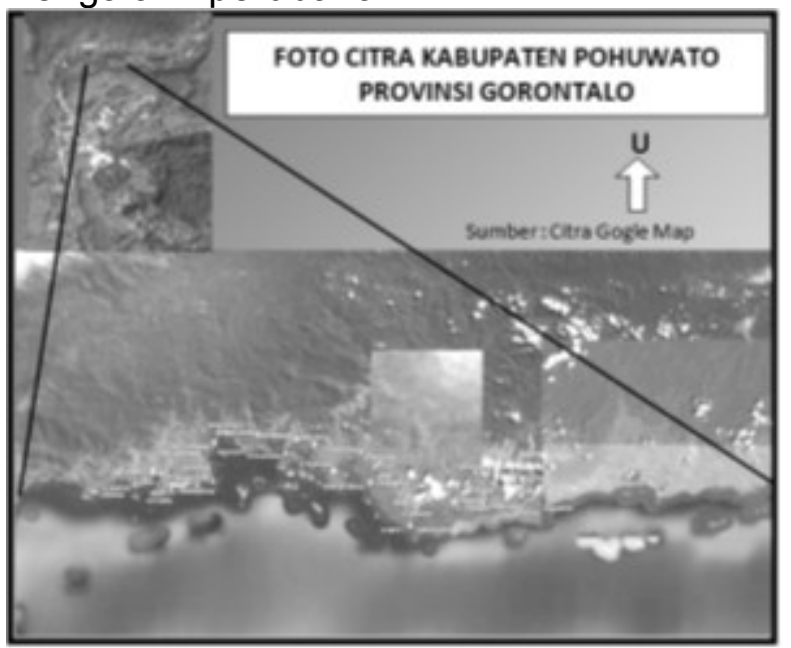

Gambar 1. Foto citra Lokasi Penelitian dengan titiktitik sampel

Tahapan pengolahan citra dalam penelitian ini disajikan pada Gambar 2 berikut ini:

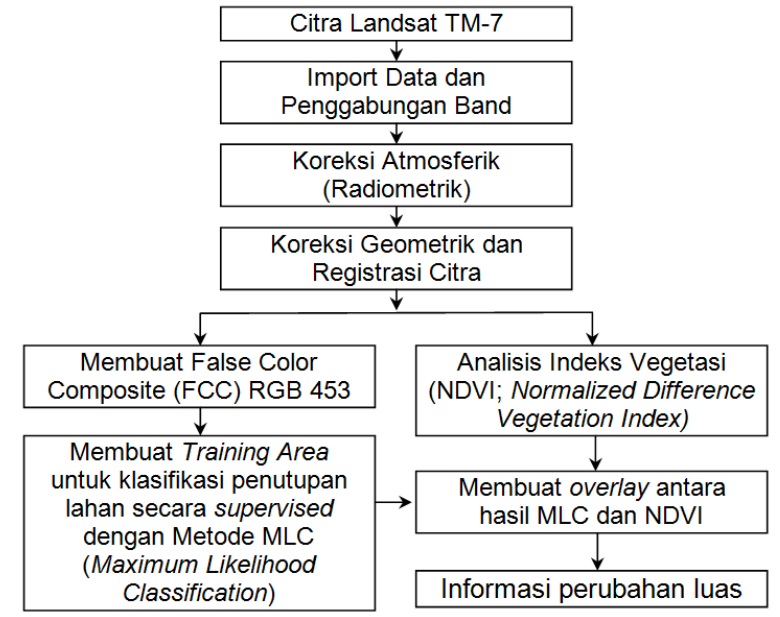

Gambar 2. Tahapan pengolahan dan analisis data secara digital.
Pantulan setiap obyek memiliki karakteristik tertentu untuk setiap saluran spektral sehingga setiap obyek dapat dikenali perbedaannya (Lillesand dan Kiefer, 1997). Hampir seluruh obyek terestrial memiliki pantulan baur, kecuali obyek air yang memiliki pantulan sempurna. Namun demikian, pada panjang gelombang mikro terjadi sebaliknya dimana obyek terestrial memiliki pantulan sempurna. Gambar 3 menunjukkan kurva pantulan spektral ideal untuk vegetasi sehat, tanah dan air. Karakteristik vegetasi dikenali dengan menggunakan perbandingan antara spektrum band merah dengan infra merah dekat. (Sutanto, 1983).

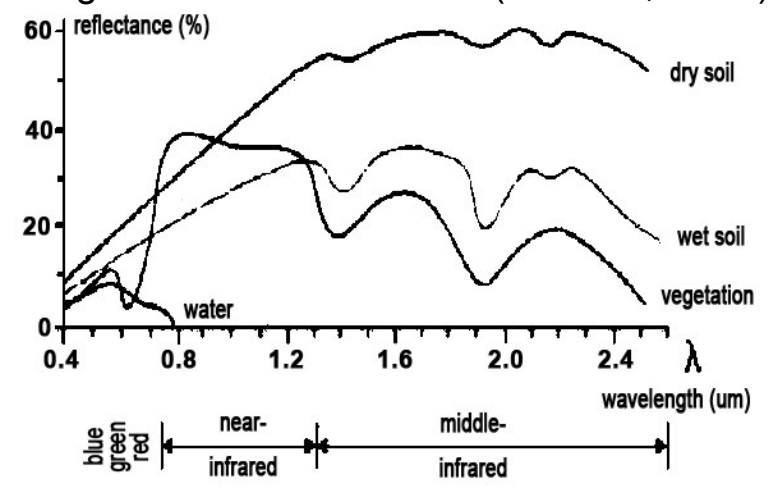

Gambar 3. Reflektansi obyek pada berbagai Panjang Gelombang. Kurva pantulan spektral ideal untuk vegetasi sehat, tanah, dan air.

Ekosistem mangrove adalah salah satu obyek yang bisa diidentifikasi dengan menggunakan teknologi penginderaan jauh. Letak geografi ekosistem mangrove yang berada pada daerah peralihan darat dan laut memberikan efek perekaman yang khas jika dibandingkan obyek vegetasi darat lainnya. Efek perekaman tersebut sangat erat kaitannya dengan karakteritik spektral ekosistem mangrove. Dalam identifikasi ekosistem mangrove memerlukan suatu transformasi tersendiri, dan dalam penelitian ini digunakan transformasi indeks vegetasi (Danoedoro, 1996).

Indeks vegetasi merupakan suatu algoritma yang diterapkan terhadap citra satelit untuk menonjolkan aspek kerapatan vegetasi ataupun aspek lain yang berkaitan dengan kerapatan, misalnya biomassa, Leaf Area Index (LAI), konsentrasi klorofil. Lebih praktis, indeks vegetasi adalah suatu transformasi matematis yang melibatkan beberapa saluran sekaligus untuk menghasilkan citra baru yang lebih representatif 
dalam menyajikan aspek-aspek yang berkaitan dengan vegetasi (Danoedoro, 1996).

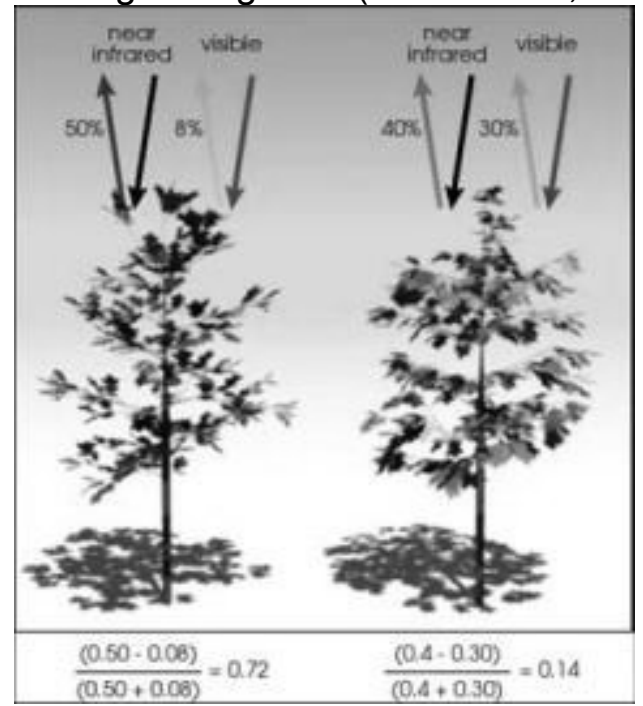

Gambar 4. Indeks Vegetasi (NDVI) dengan 2 panjang gelomban; Inframerah dekat dan Merah pada 2 macam obyek

Citra Landsat TM kabupaten Pohuwato terdapat dalam 2 scene yang terpisah, sehingga keduanya perlu digambungkan untuk mendapatkan citra kabupaten Pohuwato yang lengkap dan siap untuk dianalisis.

Kesalahan citra akibat adanya gangguan atsmosfer dan distorsi harus dihilangkan agar data yang diterima tepat seperti keadaan di lapangan. Proses ini terdiri dari koreksi radiometrik dan koreksi geometrik. Teknik koreksi radiometrik, bertujuan untuk menghilangkan kesalahan akibat pengaruh atmosfer. Teknik koreksi yang digunakan yaitu teknik penyesuaian histogram (histogram adjustment). Koreksi Geometrik bertujuan untuk menghilangkan distorsi pada citra yang disebabkan karena kelengkungan bumi, ketinggian sensor, dan ketidakstabilan sensor. Koreksi geometrik ini menggunakan analisis titik kontrol tanah (GCP), dengan acuan data citra tahun 2000 yang telah terkoreksi sebelumnya. Masingmasing citra kemudian dilakukan transformasi koordinat dengan tingkat kesalahan (Root Mean Error/RMS) antara 0.01-0.99 atau kurang dari 1. Lalu dilakukanlah pengisian gab dan masking untuk memperoleh hasil citra seperti pada Gambar 5 dan 6 .

Untuk melakukan klasifikasi terbimbing (MLC), citra gabungan ini dibuat False color composite yang terdiri dari gabungan Band 4, 5 dan 3 (RGB). Dipilinnya band 4, 5 dan 3, disebabkan karena band tersebut peka dan mempunyai nilai reflektansi yang tinggi terhadap vegetasi. Setelah itu dilakukan penajaman citra untuk memudahkan pengenalan objek secara visual.

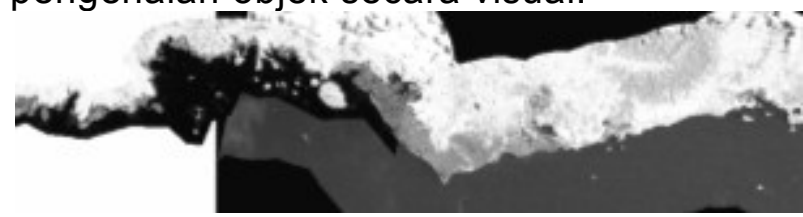

Gambar 5. Citra False Color Composite (gabungan band 4, 5 dan 3) tahun 2000-2001 kabupaten Pohuwato hasil gabungan 2 scene.

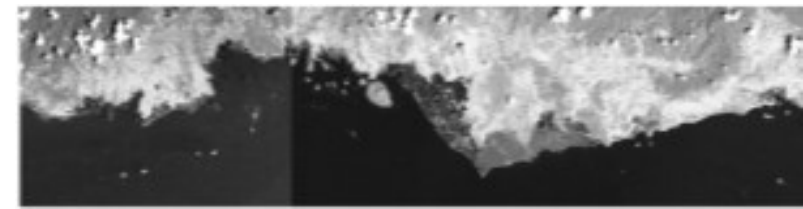

Gambar 6. Citra False Color Composite (gabungan band 4, 5 dan 3) Tahun 2009-2010 kabupaten Pohuwato hasil gabungan 2 scene

Proses selanjutnya setelah penentuan penampakan citra hasil komposit, dilakukan proses klasifikasi. Pada tahap awal dilakukan training area untuk mengelompokan pixel-pixel yang berwarna sama. Setiap hasil penandaan daerah tertentu diberikan nama (identitas) berdasarkan kenampakannya. Pixel-pixel atau warna yang tidak sesuai akan dimasukkan ke dalam kelas yang mempunyai kesamaan yang paling banyak. Proses klasifikasi ini dinamakan klasifikasi terbimbing (supervised classification) dengan metode Maximum Likelihood Classification (MLC). Hasil klasifikasi terbimbing ini dicocokkan dengan pengamatan lapangan dan menghasilkan beberapa kelas tutupan lahan seperti air, terumbu karang, hutan mangrove, hutan daratan, dan pemukiman.

\section{HASIL DAN PEMBAHASAN}

Dari hasil kalsifikasi citra Kabupaten Pohuwato didapat kelas mangrove, dengan menghitung jumlah pixel mangrove dan dikalikan dengan $900 \mathrm{~m}^{2}$ (resolusi spasial citra Landsat TM, $30 \mathrm{~m}, 1$ pixel $=30 \times 30 \mathrm{~m}$ ) didapat luas hutan mangrove pada citra Tahun 2000-2001 dan 2009-2010 hasilnya seperti terlihat pada Tabel 1.

Luas keseluruhan hutan mangrove di kabupaten Pohuwato pada tahun 20002001 adalah 7.007,67 hektar, sedangkan pada tahun 2009-2010 berkurang menjadi 
3.034,53 hektar. Seperti terlihat pada Gambar 7.

Tabel 1. Luas mangrove tahun 2000-2001 dan tahun 2009-2010

\begin{tabular}{ccc}
\hline Tahun & $\begin{array}{c}\text { Banyaknya } \\
\text { Pixel } \\
\text { Mangrove }\end{array}$ & $\begin{array}{c}\text { Luas Hutan } \\
\text { Mangrove } \\
\text { Kab. Pohuwato }\end{array}$ \\
\hline $2000-2001$ & 77.863 pixel & $7.007,67$ ha \\
$2009-2010$ & 33.717 pixel & $3.034,53$ ha \\
\hline
\end{tabular}

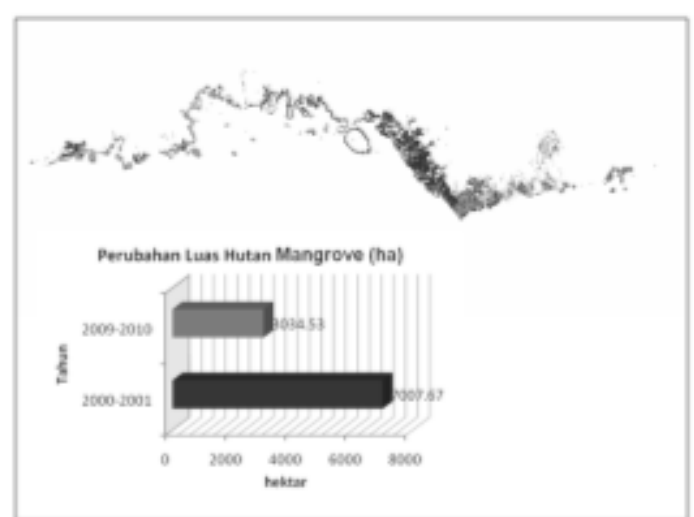

Gambar 7. Perubahan luas hutan mangrove dari tahun 2000-2001 s/d tahun 2009-2010.

Selang sepuluh tahun terjadi pengurangan luas hutan mangrove sebanyak $3.973,14$ hektar $(56,79 \%)$. Hal ini terjadi akibat pengrusakan/pembongkaran hutan mangrove yang sangat intensif dengan membuka lahan tambak, pemukiman baru.

\section{KESIMPULAN}

Luas hutan mangrove Kabupaten Pohuwato Propinsi Gorontalo yang teridentifikasi lewat citra pada tahun 2000-2001 seluas $7.007,67$ hektar dan pada tahun 2009-2010 seluas $3.034,53$ hektar. Terjadi pengurangan luas hutan mangrove sebesar $3.973,14$ hektar.

\section{DAFTAR PUSTAKA}

Campbell, J. B., 1996. Introduction to Remote Sensing. Second edition. London: Taylor \& Francis Ltd.
Dahuri, R., J. Rais, S. Putra Ginting dan M.J. Sitepu. 2004. Pengelolaan Sumberdaya Wilayah Pesisir dan Lautan Secara Terpadu. P.T.Pradnya Paramita: Jakarta. 328 hal.

Danoedoro. P, 1996. Pengolahan Citra Digital, Teori dan Aplikasinya dalam Penginderaan Jauh. Fakultas Geografi Universitas Gadjah Mada, Yogyakarta. 253 hal

Djamaluddin, R. 2010. Kondisi Ekosistem Mangrove di Kabupaten Pohuwato Provinsi Gorontalo. Makalah seminar. 15 hal.

FAO (Food and Agriculture Organization of the UN), 2000. Global mangrove statistics, http://www.fao.org.

Jaya. I.N.S. 2002. Penginderaan Jauh Satelit untuk Kehutanan. Laboratorium Inventarisasi Hutan, Jurusan Manjemen Hutan, Fakultas Kehutanan IPB

Jensen. J,R., 1998. Introductory Digital Image Processing, A Remote Sensing Perspective. Prentice Hall. New Jersey. 316p

Lillesand dan Kiefer, 1997. Penginderaan Jauh dan Interpretasi Citra. Dulbahri (Penerjemah). Gadjah Mada University Press, Yogyakarta.

Santoso Urip, 2008. Hutan Mangrove, Permasalahan dan Solusinya, uripsantoso.wordpress.com

Susilo, S. B. 1997. Penginderaan Jauh untuk mangrove. Fakultas Perikanan IPB. Bogor, 24 hal.

Sutanto, 1983 Pengenalan Pola Spektral, Yogyakarta: Fakultas Geografi-UGM

Swain. P. H and Davis, S. M (ed)., 1978. Remote Sensing the Quantitative Approach. British Library Cataloguing in Publication Data, Mcgraw-Hill. New York. 395p. 